\title{
Sleep and salivary cortisol in preterm neonates: a clinical, randomized, controlled, crossover study
}

\author{
Sono e cortisol salivar em prematuros: ensaio clínico, randômico, controlado, cruzado \\ Sueño y cortisol salival en prematuros: ensayo clínico, aleatorio, controlado, cruzado
}

\section{Fabrícia Magalhães Araújo', Mavilde da Luz Gonçalves Pedreira', Ariane Ferreira Machado Avelar', Márcia Lurdes de Cácia Pradella-Hallinan", Miriam Harumi Tsunemi"I, Eliana Moreira Pinheiro' \\ ' Universidade Federal de São Paulo, Escola Paulista de Enfermagem. São Paulo, Brazil. \\ "Universidade Federal de São Paulo, Escola Paulista de Medicina. São Paulo, Brazil. \\ I" Universidade Estadual Paulista Júlio de Mesquita Filho, Institute of Biosciences. Botucatu, São Paulo, Brazil.}

How to cite this article:

Araújo FM, Pedreira MLG, Avelar AFM, Pradella-Hallinan MLC, Tsunemi MH, Pinheiro EM. Sleep and salivary cortisol in preterm neonates: a clinical, randomized, controlled, crossover study. Rev Bras Enferm [Internet]. 2018;71(Suppl 3):1358-65.

[Thematic Issue: Health of woman and child] DOI: http://dx.doi.org/10.1590/0034-7167-2017-0546

Submission: 08-03-2017 Approval: 10-07-2017

\section{ABSTRACT}

Objective: Analyze the influence of ear protectors on the baseline levels of salivary cortisol and response and total sleep time of preterm neonates during two periods of environmental management of a neonatal intermediate care unit. Method: A clinical, randomized, controlled and crossover study conducted with 12 preterm neonates. The use of ear protectors was randomized in two periods. Sleep evaluation was performed using one Alice 5 Polysomnography System and unstructured observation. Results: No significant difference was observed between the baseline levels of salivary cortisol and response in preterm neonates from the control and experimental groups, and no statistical significance was observed between the total sleep time of both groups. No relationship was observed between the baseline levels of cortisol and response and total sleep time. Conclusion: Ear protectors in preterm neonates did not influence the salivary cortisol level and total sleep time in the studied periods.

Descriptors: Infant, Premature; Hydrocortisone; Sleep; Nursing Care; Stress, Physiological.

\section{RESUMO}

Objetivo: Verificar a influência do uso de protetores auriculares nos níveis de cortisol salivar basal e resposta e no tempo total de sono de prematuros durante dois períodos de manejo do ambiente de uma unidade de cuidado intermediário neonatal. Método: Ensaio clínico, randomizado, controlado e cruzado conduzido em 12 prematuros. O uso de protetores auriculares foi randomizado em dois períodos. A avaliação do sono foi realizada por meio do polissonígrafo Alice 5 e da observação não estruturada. Resultados: Não houve diferença significante entre os níveis de cortisol salivar basal e resposta nos prematuros dos grupos controle e experimental, não havendo também significância estatística entre o tempo total de sono dos dois grupos. Não foi observada relação entre os níveis de cortisol basal e resposta e o tempo total de sono. Conclusão: Os protetores auriculares nos prematuros não influenciaram o nível de cortisol salivar e o tempo total de sono nos períodos estudados.

Descritores: Recém-Nascido Prematuro; Hidrocortisona; Sono; Cuidados de Enfermagem; Estresse Fisiológico.

\section{RESUMEN}

Objetivo: Certificar la influencia del uso de protectores auriculares en los niveles de cortisol salival basal y la respuesta y en el tiempo total de sueño de prematuros durante dos períodos de manejo del ambiente de una unidad de cuidado intermedio neonatal. Método: Ensayo clínico, aleatorio, controlado y cruzado conducido en 12 prematuros. El uso de protectores auriculares ha sido aleatorio en dos períodos. La evaluación del sueño ha sido realizada por medio del aparato de polisomnografía Alice 5 y de la observación no estructurada. Resultados: No ha habido diferencia significante entre los niveles de cortisol salival basal y la respuesta en los prematuros de los grupos control y experimental, no habiendo también significancia estadística entre el tiempo total de sueño de los dos grupos. No ha sido observada la relación entre los niveles de cortisol basal y la respuesta y el 
tiempo total de sueño. Conclusión: Los protectores auriculares en los prematuros no han influenciado el nivel de cortisol salival y el tiempo total de sueño en los períodos estudiados.

Descriptores: Recien Nacido Prematuro; Hidrocortisona; Sueño; Atención de Enfermería; Estrés Fisiológico.

\section{CORRESPONDING AUTHOR_Eliana Moreira Pinheiro_E-mail: pinheiro@unifesp.br}

\section{INTRODUCTION}

Sleep is an essential physiological need for proper development of newborns, especially preterm neonates, since it contributes to body homeostasis and well-being ${ }^{(1)}$, and it is essential for neurological maturation, preservation of brain plasticity, long-term memory consolidation, and the establishment of emotional health and immune function, and it contributes to cellular restoration in preterm neonates (PTN) $)^{(2-4)}$.

Preterm neonates present polyphasic sleep, alternating three stages: active, quiet, and indeterminate ${ }^{(5)}$. During these stages, physiological changes occur in the body, such as a decrease in the level of cortisol, a corticosteroid hormone produced by the hypothalamic-pituitary-adrenal axis ${ }^{(6-7)}$.

Cortisol is an important biological marker of stress response in neonates ${ }^{(8)}$. The cortex of adrenal glands is responsible for the secretion of this hormone present in blood plasma and bound to carrier proteins, but cortisol can also be detected in its free form, in urine and salivary secretion ${ }^{(9-10)}$. The analysis of free salivary cortisol level in PTNs has been widely used in clinical studies because it is a noninvasive practice ${ }^{(7)}$.

This glucocorticoid, just like sleep, is controlled by the circadian cycle, but as it is absent in neonates, the release of salivary cortisol oscillates during the 24 hours $^{(7,11)}$.

Increased cortisol level causes important physiological and behavioral changes, such as increased metabolic rate, with consequent loss of body mass, glucose tolerance, increased frequency of apnea and higher intracranial pressure, and it may cause intraventricular hemorrhage. In addition, it causes reduced perception of painful stimuli and increased irritability and crying ${ }^{(8)}$.

During hospitalization, PTNs are exposed to excessive stimuli - constant presence of lighting, high levels of sound pressure in the environment and inside the incubators, constant handling and ambient temperature variation - which can generate stress and trigger frequent interruptions of sleep cycles ${ }^{(2,5,12)}$.

Although the literature clearly shows the various stimuli from both neonatal unit and care environments may cause stress and sleep deprivation in neonates, a lack of knowledge of clinical studies correlating the level of salivary cortisol with sleep variables of preterm neonates during hospitalization.

Based on the relationship between stress and sleep and its importance for infant development, studies are required to enable the implementation of more comprehensive protocols to guide the clinical practice, aiming to protect and promote sleep and the consequent development of hospitalized neonates.

\section{OBJECTIVE}

Analyze the influence of ear protectors (EPs) on the salivary cortisol level of PTNs, on the total sleep time and respective sleep stages during two periods of environmental management.

\section{METHOD}

\section{Ethical aspects}

This study was approved by the Research Ethics Committee of Universidade Federal de São Paulo and registered in Clinical Trials. Data collection started after an informed consent form was signed by the legal guardians of the neonates.

\section{Design, study site and period}

This is a randomized controlled crossover study conducted in a neonatal intermediate care unit (NICU) of a university hospital in São Paulo. This unit has some strategies of developmental care, such as minimum neonate handling and environmental management in two specific periods of the day to ensure the sleep and rest of the PTNs. This strategy, called "sleep time," is performed in the morning (10 am to $11 \mathrm{am}$ ) and in the afternoon ( 4 pm to $5 \mathrm{pm}$ ). In these periods, the multidisciplinary team of the NICU avoids handling the neonates, as far as possible, reduces lighting in the environment, and minimizes the noise level inside the rooms. Data collection was conducted between July 2013 and February 2015.

\section{Population and sample}

The study sample consisted of PTNs of gestational age of less than 37 weeks, at least 72 hours of life, weight between 1,200 and 2,000 g, who were in incubators, presenting clinically stable conditions, with test of otoacoustic emission evoked by the presence of transient stimulus. Neonates in phototherapy, invasive and non-invasive mechanical ventilation, presenting congenital malformations, periventricular hemorrhage grades II, III and IV, who took a depressor of the central nervous system, analgesic or corticoid medication were excluded from the study, as well as those whose mothers had a history of using illicit drugs during pregnancy. The CONSORT diagram was used to include preterm neonates in the study. The inclusion and exclusion criteria were defined with the purpose to eliminate possible influences on sleep and the salivary cortisol level.

The sample was calculated by assuming the use of EPs during environmental management periods reduces the level of salivary cortisol and favors extended total sleep time of PTNs. Then, the calculation was based on nine samples of saliva initially obtained in the environmental management periods in the morning shift from PTNs who used or did not use EPs. It should be noted that, in some samples collected from this initial sample, the amount of saliva required for cortisol level analysis was not obtained; then, the minimum value of $0.5 \mathrm{ng} / \mathrm{ml}$ detectable in the ELISA test was accepted for sample calculation.

The mean values of cortisol level before $(2.29 \pm 1.44 \mathrm{ng} /$ $\mathrm{ml})$ and after $(1.17 \pm 0.93 \mathrm{ng} / \mathrm{ml})$ of the intervention provided a difference of $1.12 \mathrm{ng} / \mathrm{ml}$. Considering this difference, the 
significance level of $5 \%$, and $80 \%$ statistical power, it would take 12 PTNs to detect this difference with a statistically significant result. The paired t-test of STATISTICA ${ }^{\circledR}$ software, Oklahoma, USA, was used to calculate the sample.

Saliva samples were collected from 32 PTNs. However, due to insufficient amount of saliva collected for the cortisol level analysis, only 12 preterm neonates were included in the study, observing the sample calculation guidelines.

\section{Study protocol}

The experimental variable is the use of EP in PTNs during one of the NICU environment management periods, constituting the experimental group. The EPs used in the study were MiniMuffs ${ }^{\circledast}$ Neonatal Noise Attenuators, manufactured by Natus ${ }^{\circledast}$ Pediatrics, California, USA, which reduce the sound pressure levels from 7 to 12 decibels $^{(13-15)}$.

EPs are oval-shaped anatomical devices that allow proper positioning on the ears. They have soft foam and hydrogel adhesive on the outer edges for skin attachment. Considering the possibility of detachment of these devices in the PTNs, a substance with polyethylene and cellulose was used, which helps protect the skin and improves the adhesion of the protectors. The EPs were placed on the PTNs by one of the researchers, on average 12 minutes before starting the NICU environmental management, and removed immediately after the end of these periods.

The control group consisted of PTNs that did not use EPs during one of the periods of NICU environment management.

The salivary cortisol levels of PTNs with and without the use of PAs before the start (baseline cortisol) and at the end (cortisol response) of environmental management periods and total sleep time and respective sleep stages were the outcome variables.

Saliva was collected from the PTNs with the help of ophthalmic sponges (Merocel ${ }^{\circledR}$, USA) of high capacity of absorption of body fluids, attached to a flexible $\operatorname{rod}^{(16)}$. Two initial samples were obtained 20 minutes before the environmental management period (baseline cortisol) and two samples were collected immediately after the end of the same period (cortisol response), before the removal of EPs, totalizing four samples from each neonate. Prior to collection, all neonates underwent oral hygiene with gauze and sterile water to remove milk residues that could influence the analysis ${ }^{(17)}$. The procedure of saliva collection from the oral cavity was performed by one of the researchers and lasted, on average, eight minutes.

All saliva samples were placed in Eppendorf tubes and stored under refrigeration, with the sponges upwards, and sent to the laboratory for analysis. The samples were centrifuged at $3,000 \mathrm{rpm}$ for 5 minutes in a refrigerated device and stored in a freezer at $-18^{\circ} \mathrm{C}$ to $-20^{\circ} \mathrm{C}$ until the analysis ${ }^{(16,18)}$.

The laboratory analysis used the ELISA method, which determines the direct immunoenzymatic concentration of cortisol. In this method, the minimum sensitivity for the detection of salivary cortisol level is $0.5 \mathrm{ng} / \mathrm{ml}^{(19)}$.

The evaluation of total sleep time and respective sleep stages (active, quiet or indeterminate) used one Alice 5 Polysomnography System (Philips Respironics ${ }^{\circledast}$, Pennsylvania, USA), an instrument that performs sleep records of $\mathrm{PTNs}^{(20)}$. The installation of this system on the PTNs was performed by a polysomnography expert. This procedure started, on average, two hours before the morning environmental management period. Sleep data records started, on average, one hour before the beginning of the environmental management, and after that, they were continuously recorded until the researcher finished the last collection of saliva after the afternoon environmental management.

The polysomnography analysis observed the guidelines from the American Academy of Sleep Medicine (AASM), version 2.0, and it was performed by a pediatric neurologist specialized in sleep medicine ${ }^{(21)}$.

Each PTN was submitted to two periods of environmental management, using the EPs (experimental group) in one period, and not using the EPs in the other period (control group). Randomization was obtained using the Latin square design method, which enabled the distribution of the use or non-use of EPs in the two periods of NICU environmental management.

\section{Result analysis and statistics}

Data collected were stored in Microsoft Excel ${ }^{\circledR}$ software and analyzed in SPSS Statistics ${ }^{\circledR} 20.0$, Chicago, USA, using descriptive statistical analysis, parametric tests (paired t-test), and linear regression when the required prerequisites were met for these tests (normality and homogeneity). Then, the effect of total sleep time and baseline levels of salivary cortisol and response on independent variables was estimated. Non-parametric test (Spearman's correlation) was performed to evaluate the strength of the relationship between the variables. The $R$ Program, New Zealand - USA, was also used in the construction of mixed linear models to evaluate whether the random effect of using ear protectors was the same on each neonate. All analyses used significance level of $5 \%(p \leq 0.05)$.

\section{RESULTS}

Table 1 shows the demographic and clinical characteristics of the PTNs that met the eligibility criteria defined for this study.

The neonates presented moderate prematurity, most of them classified as small for the gestational age, and very low birth weight. Cesarean delivery and female preterm neonates were predominant. Of note, more than half mothers used prenatal corticosteroid, and the same proportion of PTNs used caffeine during hospitalization.

The baseline levels of salivary cortisol and response of the PTNs from the control and experimental groups during the environmental management periods of the neonatal unit did not present a statistically significant difference (Table 2). However, the mean values of these levels show a more significant reduction of the values in the control group when compared to the experimental group.

Spearman's linear correlation test shows a strong relationship between baseline levels of salivary cortisol and response of PTNs during the environmental management periods in the control $(\rho=0.727 ; p=0.007)$ and experimental $(\rho=0.848$, $p=<0.001$ ) groups, indicating that a high level of baseline salivary cortisol tends to remain within the salivary cortisol response, regardless of the intervention. 
Table 1 - Characteristics of preterm neonates evaluated in this study, São Paulo, Brazil

\begin{tabular}{lcc}
\hline \multicolumn{1}{c}{ Variables } & Mean \pm SD & $\mathbf{n}(\mathbf{\%})$ \\
\hline Age & & \\
Gestational age acc. to LMP (weeks) & $32.5 \pm 2.1$ & $12(100.0)$ \\
Gestational age acc. to LMP - corrected (weeks) & $33.0 \pm 1.4$ & $12(100.0)$ \\
Chronological age (days) & $18.3 \pm 6.7$ & $12(100.0)$ \\
Weight & & \\
At birth (grams) & $1499.2 \pm 330.4$ & $12(100.0)$ \\
Current (grams) & $1635.4 \pm 218.7$ & $12(100.0)$ \\
Birth & & \\
Cesarean & - & $11(91.7)$ \\
Vaginal & & $1(8.3)$ \\
Sex & - & $8(66.7)$ \\
Female & - & $4(33.3)$ \\
Male & & \\
Size according to the gestational age & - & $8(66.7)$ \\
SGA & - & $4(33.3)$ \\
AGA & - & \\
Diagnosis & - & $6(50.0)$ \\
Respiratory & - & $4(33.3)$ \\
Hematologic & - & $2(16.7)$ \\
Digestive & - & $7(58.3)$ \\
Use of pre-natal corticosteroid & - & $5(41.7)$ \\
Yes & - & \\
No & - & \\
Use of caffeine & & \\
Yes & - & \\
No & - & \\
\hline
\end{tabular}

Note: SD - standard deviation; LMP - last menstrual period; SGA - small for gestational age; AGA - adequate for gestational age.

Table 2 - Baseline levels of salivary cortisol and response of preterm neonates from the control and experimental groups during the environmental management periods of a neonatal unit, São Paulo, Brazil

\begin{tabular}{|c|c|c|c|c|}
\hline \multirow[b]{2}{*}{ Coefficients } & \multicolumn{2}{|c|}{ Control group } & \multicolumn{2}{|c|}{ Experimental group } \\
\hline & $\begin{array}{l}\text { Baseline } \\
\text { salivary cortisol } \\
(\mathrm{ng} / \mathrm{ml})\end{array}$ & $\begin{array}{l}\text { Salivary cortisol } \\
\text { response } \\
(\mathrm{ng} / \mathrm{ml})\end{array}$ & $\begin{array}{c}\text { Baseline } \\
\text { salivary cortisol } \\
(\mathrm{ng} / \mathrm{ml})\end{array}$ & $\begin{array}{l}\text { Salivary cortisol } \\
\text { response } \\
(\mathrm{ng} / \mathrm{ml})\end{array}$ \\
\hline & 0.532 & 0.398 & 7.004 & 2.782 \\
\hline & 2.989 & 2.098 & 3.765 & 1.798 \\
\hline & 0.300 & 0.310 & 2.071 & 2.343 \\
\hline & 2.361 & 2.733 & 0.285 & 0.172 \\
\hline & 1.358 & 2.875 & 0.050 & 0.050 \\
\hline & 0.050 & 1.535 & 0.050 & 0.643 \\
\hline & 1.158 & 3.531 & 2.546 & 2.169 \\
\hline & 1.852 & 1.843 & 2.681 & 6.021 \\
\hline & 3.651 & 5.707 & 3.941 & 4.701 \\
\hline & 0.306 & 0.267 & 0.408 & 0.158 \\
\hline & 1.583 & 0.899 & 1.449 & 0.275 \\
\hline & 18.37 & 6.667 & 1.711 & 1.477 \\
\hline Mean $\pm S D$ & $2.88 \pm 5.01$ & $2.41 \pm 2.07$ & $2.16 \pm 2.04$ & $1.88 \pm 1.90$ \\
\hline$p$ value & 0.6 & 68 & 0.594 & \\
\hline
\end{tabular}

Note: $S D$ - standard deviation.
The total sleep time of PTNs was higher in the control group, mean of 5.3 minutes more when compared to the neonates from the experimental group. Regarding the sleep stages, the predominance of quiet sleep was observed in both groups. The use of EPs in preterm neonates did not show statistical significance between the two groups analyzed in this study (Table 3).

Spearman's linear correlation between the total sleep time and sleep stages showed a strong relationship only with active sleep in the experimental group ( $\rho=0.617 ; p=0.033$ ), indicating that longer total sleep time in the PTNs is related to more frequent active sleep. In the control group, a moderate relationship was observed between the total sleep time and quiet sleep ( $\rho=0.560 ; p=0.058$ ).

Table 4 presents the relationship between baseline salivary cortisol and response and total sleep time of neonates during the environmental management periods in the control and experimental groups. This relationship is not strong and negative in both groups. Even without statistical significance, this negative correlation indicates that the high level of cortisol implies a shorter sleep time of the PTNs in both groups.

The behavior of the variables: gestational age corrected by the last menstrual period (LMP), current weight, non-use of caffeine by the PTNs and prenatal corticosteroid by the mothers of the neonates in relation to the total sleep time and baseline salivary cortisol and response was estimated using multiple linear regression and did not show statistical significance. However, the control group showed a 7-minute increase in total sleep time of the PTNs whose mothers did not use prenatal corticosteroids and 2.1 minutes in the absence of caffeine. In the experimental group, the increase in total sleep time was 0.8 minutes and 2.3 minutes for the respective criteria. This model explains $13.53 \%$ of the variation in total sleep time.

The linear regression analysis of baseline levels of salivary cortisol and response with the same variables shows a trend towards reduced levels in PTNs who were not exposed to these substances, except for salivary cortisol response in the experimental group not exposed to caffeine, with tendency to increased level $(2.2 \mathrm{ng} / \mathrm{ml})$. This analysis explains $15.4 \%$ of baseline levels of salivary cortisol and response of the neonates.

The evaluation of the mean frequency of central apneas during the environmental management periods using the paired t-test showed a higher occurrence in the control group $(M=37.4 \pm 31.6)$ when compared to the experimental group $(M=22.9 \pm 26.0), p=0.028$. 
Table 3 - Total sleep time and respective sleep stages, in minutes, of the preterm neonates from the control and experimental groups during the environmental management periods of a neonatal unit, São Paulo, Brazil

\begin{tabular}{|c|c|c|c|c|}
\hline Study groups & Total sleep time & Active sleep & Quiet sleep & $\begin{array}{c}\text { Indeterminate } \\
\text { sleep }\end{array}$ \\
\hline \multirow{12}{*}{ Control group } & 49.0 & 15.0 & 30.0 & 4.0 \\
\hline & 54.5 & 29.5 & 18.5 & 6.5 \\
\hline & 52.0 & 37.0 & 5.5 & 9.5 \\
\hline & 47.0 & 4.0 & 22.5 & 20.5 \\
\hline & 55.0 & 12.5 & 33.0 & 9.5 \\
\hline & 34.0 & 6.0 & 21.0 & 7.0 \\
\hline & 44.5 & 28.0 & 7.0 & 9.5 \\
\hline & 52.5 & 3.0 & 38.5 & 11.0 \\
\hline & 32.0 & 3.0 & 15.0 & 14.0 \\
\hline & 54.0 & 13.0 & 29.0 & 12.0 \\
\hline & 44.5 & 15.0 & 16.5 & 13.0 \\
\hline & 40.0 & 27.5 & 4.5 & 8.0 \\
\hline \multirow[t]{2}{*}{ Mean $\pm S D$} & $46.6 \pm 7.9$ & $16.1 \pm 11.7$ & $20.1 \pm 11.1$ & $10.4 \pm 4.3$ \\
\hline & 45.0 & 11.5 & 16.0 & 17.5 \\
\hline \multirow{11}{*}{ Experimental group } & 29.5 & 0.0 & 20.5 & 9.0 \\
\hline & 44.0 & 25.5 & 13.0 & 5.5 \\
\hline & 31.5 & 0.0 & 13.0 & 18.5 \\
\hline & 54.0 & 6.5 & 36.5 & 11.0 \\
\hline & 46.5 & 25.5 & 15.0 & 6.0 \\
\hline & 55.5 & 27.0 & 23.5 & 5.0 \\
\hline & 39.0 & 0.0 & 26.5 & 12.5 \\
\hline & 33.5 & 11.5 & 13.0 & 9.0 \\
\hline & 33.5 & 10.5 & 13.0 & 10.0 \\
\hline & 39.5 & 25.0 & 6.5 & 8.0 \\
\hline & 44.0 & 10.0 & 23.5 & 10.5 \\
\hline Mean \pm SD & $41.3 \pm 8.4$ & $12.8 \pm 10.5$ & $18.3 \pm 8.1$ & $10.2 \pm 4.3$ \\
\hline$p$ value & 0.149 & 0.381 & 0.613 & 0.913 \\
\hline
\end{tabular}

Note: $S D$ - standard deviation.

Table 4 - Spearman's linear correlation coefficient between total sleep time and baseline levels of salivary cortisol and response of preterm neonates from the control and experimental groups in the environmental management periods of a neonatal unit, São Paulo, Brazil

\begin{tabular}{clllll}
\hline & \multicolumn{2}{c}{$\begin{array}{c}\text { Control group } \\
(\mathbf{n}=\mathbf{1 2})\end{array}$} & \multicolumn{2}{c}{$\begin{array}{c}\text { Experimental group } \\
(\mathbf{n}=\mathbf{1 2})\end{array}$} \\
& Variables & $\begin{array}{c}\text { Correlation } \\
\text { coefficient }\end{array}$ & $\boldsymbol{p}$ value & $\begin{array}{c}\text { Correlation } \\
\text { coefficient }\end{array}$ & $\boldsymbol{p}$ value \\
\hline \multirow{2}{*}{ TST } & Baseline salivary cortisol & -0.154 & 0.632 & -0.214 & 0.503 \\
& Salivary cortisol response & -0.371 & 0.235 & -0.035 & 0.914 \\
\hline
\end{tabular}

Note: TST - total sleep time.

Table 5 - $\quad$ Relation between baseline salivary cortisol and response and total sleep time with central apnea frequency, gestational age corrected according to the last menstrual period and caffeine use by preterm neonates when using ear protectors, São Paulo, Brazil

\begin{tabular}{llccc}
\hline Variables & & Estimate & Standard error & $\boldsymbol{p}$ value \\
\hline Baseline salivary & Intercept & 0.82 & 5.65 & - \\
cortisol and & Central apnea & -0.00 & 0.01 & 0.573 \\
response & Age corrected acc. to LMP & 0.03 & 0.16 & 0.742 \\
& Use of caffeine & -0.10 & 0.71 & 0.811 \\
& Ear protector & -0.17 & 0.51 & 0.742 \\
\hline
\end{tabular}

To be continued
For a better evaluation of the frequency of central apnea and other parameters, the mixed linear models were adjusted, considering only the moment (use of ear protectors) as a random effect.

The effect of EPs on central apnea, corrected gestational age considering the LMP and use of caffeine in relation to baseline levels of salivary cortisol and response based on the factors of moment of differentiation between these levels and total sleep time of PTNs (Table 5) found statistical significance only between total sleep time and the occurrence of central apnea $(p<0.035)$.

This model shows that the occurrence of central apnea increased the total sleep time by 0.11 minutes when the EPs were used. However, no relationship was found between baseline levels of salivary cortisol and response and the variables previously mentioned at the moments when the PTNs used the EPs. These variables also did not present any type of relation with the active, quiet and indeterminate sleep stages evaluated in the mixed linear model (Table 5).

\section{DISCUSSION}

The baseline levels of salivary cortisol and response and total sleep time and the respective sleep stages did not differ significantly in relation to the use of ear protectors in the environmental management periods of the investigated NICU.

The comparison of the results of this study is limited due to the lack of other studies using a similar methodological design, and it is the first study to associate the use of EPs with the variables of salivary cortisol and sleep of PTNs, corroborated by the sleep analysis using a polysomnography system, allowing an accurate evaluation during the study period, thus contributing to result reliability.

Among the studies on the use of EPs, only two of them included sleep in the evaluated variables, showing it favors the sleep of PTNs. However, in these studies, data were collected with the application of scales that classified/quantified sleep from direct observation of the behavioral states of the neonates, thus establishing scores that range from alertness to different classifications of sleep ${ }^{(13,18)}$.

No significant correlation was observed between the baseline levels of salivary 
Table 5 (concluded)

\begin{tabular}{llccc}
\hline Variables & & Estimate & Standard error & $\boldsymbol{p}$ value \\
\hline Total sleep time & Intercept & 39.42 & 36.23 & - \\
& Central apnea & 0.11 & 0.05 & $0.035^{*}$ \\
& Age corrected acc. to LMP & 0.16 & 1.06 & 0.872 \\
& Use of caffeine & -5.63 & 4.59 & 0.229 \\
& Ear protector & -4.42 & 3.27 & 0.186 \\
\hline
\end{tabular}

Note: $L M P$ - last menstrual period; ${ }^{*} p<0.05$.

cortisol and response and total sleep time in the environmental management periods in which the PTNs used ear protectors. However, even without statistical significance, the negative correlation found in the present study indicates that total sleep time increases with reduced cortisol level, suggesting that further studies are required to evaluate this correlation.

A randomized crossover study conducted at the neonatal ICU that develops the Newborn Individualized Developmental Care and Assessment Program (NIDCAP) used the EDIN (échelle douleur inconfort nouveau-né) scale to assess stress response, sleep quality, pain, heart rate, oxygen saturation, and the impact of environmental measures through the application of some behavioral interventions such as positioning, touching, non-nutritive sucking during the weighing procedure in term neonates and PTNs. This study did not show a significant difference in baseline levels of salivary cortisol and response, but in the physiological parameters and in behavioral responses of neonates from both the control and experimental groups ${ }^{(22)}$.

The strong positive correlation between baseline levels of salivary cortisol and response of the PTNs found in this study shows that these levels practically did not vary between the control and experimental groups. Also, it was not possible to identify the presence of cortisol circadian rhythm in the environmental management periods of the NICU, which may be a consequence of the immaturity of the neonates ${ }^{(23)}$.

The duration of the environmental management periods set by the service where this study was conducted may not have been sufficient to promote the adaptation of the neonates to the EPs and the consequent reduction of the level of salivary cortisol response in the neonates. This factor may explain the absence of a statistically significant difference between the baseline levels of salivary cortisol and response in the control and experimental groups.

Studies that used EPs to evaluate behavioral aspects, such as sleep, motor response, pain and physiological parameters like body temperature, oxygen saturation, blood pressure, and heart and respiratory rates in PTNs, performed the intervention for periods of two hours or more $\mathrm{e}^{(13-15,24-25)}$.

The baseline levels of salivary cortisol and response of preterm neonates in this study did not differ significantly when compared to other studies. The literature shows absent parameters of these levels in neonates of different gestational ages ${ }^{(17,26)}$.

When evaluating the mean values of total sleep time and the different sleep stages, the control group showed a longer time of quiet sleep. This finding does not agree with a study that evaluated the use of EPs in PTNs and found a longer time of quiet sleep when these devices were used ${ }^{(13)}$. In addition, in the experimental group, the use of EPs favored active sleep. This unprecedented result is very important, since this sleep stage is fundamental for the PTNs, especially for their neurosensory development, indicating the need for further studies ${ }^{(1-2)}$.

A higher frequency of apnea and a longer sleep time were observed when the PTNs used the EPs. No significant relationship was observed between the occurrence of central apnea and the different sleep stages. A study that used a polysomnography system and evaluated the effect of thermoregulation on the occurrence of apnea episodes in PTNs during the quiet and active sleep stages showed a higher frequency of central apnea during active sleep, which was associated with loss of body heat ${ }^{277}$.

\section{Study limitations}

One study limitation referred to the challenge to obtain a sufficient amount of saliva for analysis due to the peculiar hyposalivation of PTNs. Further studies should be conducted for a longer period, since the time of adaptation of neonates to the EPs may not have been sufficient to show reduced salivary cortisol level.

\section{Contributions to the nursing area}

The proposed intervention allowed a longer time of active sleep to the preterm neonates.

\section{CONCLUSION}

The use of EPs on the PTNs did not influence the baseline levels of salivary cortisol and response and total sleep time during the environment management periods of an NICU. However, the use of EPs favored longer active sleep time, essential for the neurosensory development. The longer total sleep time when the PTNs used the ear protectors provided more episodes of central apnea.

\section{FUNDING}

This study was conducted with the financial support from Fundação de Amparo à Pesquisa do Estado de São Paulo (Fapesp), protocol no 2012/50365-2.

\section{REFERENCES}

1. Arditi-Babchuk H, Feldman R, Eidelman AI. Rapid eye movement (REM) in premature neonates and developmental outcome at 6 months. Infant Behav Dev [Internet]. 2009[cited 2016 Jun 15];32(1):27-32. Available from: http://www.sciencedirect.com/science/ article/ pii/S0163638308000775?via\%3Dihub

2. Dorn F, Wirth L, Gorbey S, Wege M, Zemlin M, Maier RF, et al. Influence of acoustic stimulation on the circadian and ultradian 
rhythm of premature infants. Chronobiol Int [Internet]. 2014[cited 2016 Jun 16];31(9):1062-74. Available from: http://www. tandfonline. com/doi/full/10.3109/07420528.2014.948183?scroll = top\&needAccess $=$ true

3. Calciolari G, Montirosso R. The sleep protection in the preterm infants. J Matern Fetal Neonatal Med [Internet]. 2011 [cited 2016 Jun 26];24(Suppl-1):12-4. Available from: http://www.tandfonline.com/doi/abs/10.3109/14767058.2011. 607563?journalCode=ijmf20

4. Miller DJ, Duka T, Stimpson CD, Schapiro SJ, Baze WB, McArthur MJ, et al. Prolonged myelination in human neocortical evolution. Proc Natl Acad Sci USA[Internet]. 2012[cited 2016 Jul 20];109(41):16480-5. Available from: http://www.pnas.org/content/109/41/16480.full

5. Bonan KC, Pimentel Filho JC, Tristão RM, Jesus JA, Campos Jr D. Sleep deprivation, pain and prematurity: a review study. Arq Neuropsiquiatr [Internet]. 2015[cited 2016 Jul 12];73(2):147-54. Available form: http://www.scielo.br/pdf/anp/v73n2/0004-282Xanp-73-02-147.pdf

6. Mörelius E, He HG, Shorey S. Salivary cortisol reactivity in preterm infants in neonatal intensive care: an integrative review. Int J Environ Res Public Health [Internet]. 2016[cited 2016 Jul 23];13(3):337-51. Available from: https://www.ncbi.nlm.nih.gov/pmc/ articles/ PMC4809000/pdf/ijerph-13-00337.pdf

7. Silva ML, Mallozi MC, Ferrari GF. Salivary cortisol to assess the hypothalamic-pituitary-adrenal axis in healthy children under 3 years old. J Pediatr[Internet]. 2007[cited 2016 Jun 30];83(2):121-6. Available from: http://www.jped.com.br/conteudo/07-83-02121/port.pdf

8. Tollenaar MS, Beijers R, Jansen J, Riksen-Walraven JM, Weerth C. Solitary sleeping in young infants is associated with heightened cortisol reactivity to a bathing session but not to a vaccination. Psychoneuroendocrinol[Internet]. 2012 [cited 2016 Jun 30];37(2):167-77. Available from: http://www.sciencedirect.com/science/article/pii/S0306453011001065

9. Grunau RE, Holsti L, Haley DW, Oberlander T, Weinberg J, Solimano A, et al. Neonatal procedural pain exposure predicts lower cortisol and behavioral reactivity in preterm infants in the NICU. Pain [Internet]. 2005[cited 2016 Jun 26];113(3):293-300. Available from: https://www.ncbi.nlm.nih.gov/pmc/articles/PMC1447527/

10. Herrington CJ, Olomu IN, Geller SM. Salivary cortisol as indicators of pain in preterm infants: a pilot study. Clin Nurs Res[Internet]. 2004[cited 2016 Jun 25];13(1):53-68. Available from: https://www.ncbi.nlm.nih.gov/pubmed/14768767

11. Custodio RJ, Martinelli Jr CE, Milani SL, Simões AL, Castro M, Moreira AC. The emergence of the cortisol circadian rhythm in monozygotic and dizygotic twin infants: the twin-pair synchrony. Clin Endocrinol[Internet]. 2007[cited 2016 Jun 30];66(2):192-7. Available from: https://www.ncbi.nlm.nih.gov/pmc/articles/PMC1859886/

12. Smith SL, Haley S, Slater H, Moyer-Mileur LJ. Heart rate variability during caregiving and sleep after massage therapy in preterm infants. Early Hum Dev [Internet]. 2013[cited 2016 Jul 25];89(8):525-9. Available from: https://www.ncbi.nlm.nih.gov/pmc/ articles/PMC3647010/

13. Duran R, Ciftdemir NA, Ozbek UV, Berberoğlu U, Durankuş F, Süt N, et al. The effects of noise reduction by earmuffs on the physiologic and behavioral responses in very low birth weight preterm infants. Int J Pediatr Otorhinolaryngol [Internet]. 2012[cited 2016 Jun 26];76(10):1490-3. Available from: http://www.sciencedirect.com/science/article/pii/ S0165587612003874

14. Abdeyazdan Z, Ghassemi S, Marofi M. The effects of earmuff on physiologic and motor responses in premature infants admitted in neonatal intensive care unit. Iran J Nurs Midwifery Res [Internet]. 2014[cited 2016 Jun 25];19(2):107-12. Available from: https:// www.ncbi.nlm.nih.gov/pmc/articles/PMC4020017/

15. Abujarir R, Salama H, Greer W, Thani MA, Vlisda F. The impact of earmuffs on vital signs in a neonatal intensive care unit. Neonatol Today [Internet]. 2012[cited 2016 Jun 25];7(2):1-8. Available from: http://www.neonatologytoday.net/newsletters/nt-feb12.pdf

16. Weerth C, Jansen J, Vos MH, Maitimu I, Lentjes EG. A new device for collecting saliva for cortisol determination. Psychon euroendocrinol[Internet]. 2007[cited 2016 Jun 24];32(8-10):1144-8. Available from: http://www.psyneuen-journal.com/article/ S0306-4530(07)00200-4/pdf

17. Cândia MF, Osaku EF, Leite MA, Toccolini B, Costa NL, Teixeira SN, et al. Influence of prone positioning on premature newborn infant stress assessed by means of salivary cortisol measurement: pilot study. Rev Bras Ter Intensiva[Internet]. 2014 [cited 2016 Jul 10];26(2):169-75. Available from: http://www.scielo.br/pdf/rbti/v26n2/0103-507X-rbti-26-02-0169.pdf

18. Neu M, Goldstein M, Gao D, Laudenslager ML. Salivary cortisol in preterm infants: validation of a simple method for collecting saliva for cortisol determination. Early Hum Dev [Internet]. 2007[cited 2016 Jun 25];83(1):47-54. Available from: http://www. sciencedirect.com/science/article/pii/S0378378206001319

19. DiaMetra. Cortisol Saliva for routine analysis, direct immunoenzymatic determination of cortisol in saliva [Internet]. 2017[cited 2016 Jul 10]. Available from: http://www.diametra.com/home/register.html

20. American Academy of Sleep Medicine. The AASM Manual for the Scoring of Sleep and Associated Events Rules, Terminology and Techinical Specifications. Version 2.0. Illions (US): AASM; 2012. 58 p.

21. American Academy of Sleep Medicine. International Classification of Sleep Disorders, revised. Diagnostic and coding manual. 2th ed. Westchester: AASM; 2005. 208 p.

22. Catelin C, Tordjman S, Morin V, Oger E, Sizun J. Clinical, physiologic, and biologic impact of environmental and behavioral interventions in neonates during a routine nursing procedure. J Pain [Internet]. 2005[cited 2016 Jun 26];6(12):791-7. Available from: http://50.28.28.219/wp-content/uploads/2013/12/Catelin-2005-Clinical-psychological-and-biologic.pdf

23. Antonini SR, Jorge SM, Moreira AC. The emergence of salivary cortisol circadian rhythm and its relationship to sleep activity in 
preterm infants. Clin Endocrinol[Internet]. 2000[cited 2016 Jul 6];52(4):423-6. Available from: http://onlinelibrary.wiley.com/ doi/10.1111/j.1365-2265.2000.tb00561.x/pdf

24. Aita M, Johnston C, Goulet C, Oberlander TF, Snider L. Intervention minimizing preterm infants' exposure to NICU light and noise. Clin Nurs Res [Internet]. 2013[cited 2016 Jun 27];22(3):337-58. Available from: http://journals.sagepub.com/doi/ pdf/10.1177/1054773812469223

25. Abdeyazdan Z, Ghasemi S, Marofi M, Berjis N. Motor responses and weight gaining in neonates through use of two methods of earmuff and receiving silence in NICU. Sci World J[Internet]. 2014[cited 2016 Jun 15];2014:1-5. Available from: http://dx.doi. org/10.1155/2014/864780

26. Cabral DM, Antonini SR, Custódio RJ, Martinelli Jr CE, Silva CA. Measurement of salivary cortisol as a marker of stress in newborns in a neonatal intensive care unit. Horm Res Paediatr [Internet]. 2013[cited 2016]un 30];79(6):373-8. Available from: https://www.researchgate.net/ publication/241696910_Measurement_of_Salivary_Cortisol_as_a_Marker_of_Stress_in_Newborns_in_a_Neonatal_Intensive_Care_Unit

27. Tourneux $\mathrm{P}$, Cardot V, Museux N, Chardon K, Léké A, Telliez F, et al. Influence of thermal drive on central sleep apnea in the preterm neonate. Sleep [Internet]. 2008[cited 2016 Jun 27];31(4):549-56. Available from: https://www.ncbi.nlm.nih.gov/pmc/ articles/ PMC2279750/ 